\title{
Perspectivas de mulheres em recuperação de drogas sobre o tratamento em uma comunidade terapêutica
}

\section{Women's perspectives in drug recovery on treatment in a therapeutic community}

Vagner Ferreira do Nascimento, Marciana Fernandes Moll, Rulio Glécias Marçal da Silva, Alisséia Guimarães Lemes, Juliana Fernandes Cabral, Tayane Próspero Cardoso, Margarita Antonia Villar Luis

Como citar este artigo: CABRAL, J. F.; CARDOSO, T. P.; LEMES, A. G.; LUIS, M. A. V.; MOLL, M. F.: NASCIMENTO, V. F.: SILVA, R. C. M. Perspectivas de mulheres em recuperação de drogas sobre o tratamento em uma comunidade terapêutica. Revista Saúde (Sta. Maria). 2017; 43 (3).

\section{Autor correspondente:}

Nome: Vagner Ferreira do Nascimento

E-mail: vagnerschon@hotmail.com Telefone: (66) 992230930 Formação Profissional:

Doutorando em BIOÉTICA pelo Centro Universitário São Camilo (CUSC SP), São Paulo, SP, Brasil

Filiação Institucional: Universidade do Estado de Mato Grosso

Endereço para correspondência: Rua: Moreira Cabral n: 475

Bairro: Campinas Cidade:

Barra do Garcas Estado: Mato

Grosso

CEP: 78600-000

Data de Submissão:

26/08/2016

Data de aceite:

16/11/2017

Conflito de Interesse: Não há conflito de interesse

\section{(cc) $\mathrm{BY}-\mathrm{NC}-\mathrm{ND}$}

\section{RESUMO}

O estudo objetivou conhecer a perspectiva de mulheres em recuperação de drogas sobre o tratamento em uma comunidade terapêutica. Foi realizado em março a abril de 2016 em uma comunidade terapêutica de referência da região nordeste de Mato Grosso, junto a 15 mulheres. Utilizou-se entrevista semiestruturada com auxílio de roteiro e para análise dos dados, aplicou-se a análise de conteúdo. Observou-se que as mulheres manifestaram tristeza, angústia e aflição por estarem separadas de seus familiares durante o tratamento, o que dificulta a adesão e continuidade à terapia estabelecida. Além disso, demonstraram insatisfação quanto a forma de tratamento realizada, por não considerarem as particularidades individuais de cada mulher. Porém, reconhecem que suas condições atuais na comunidade terapêutica são notadamente melhores. Novas formas de abordagem podem ser incorporadas nesse tipo de serviço, priorizando a escuta ativa da mulher e de seus familiares no acolhimento e na construção do projeto terapêutico.

PALAVRAS-CHAVE: Transtornos Relacionados ao Uso de Substâncias; Acontecimentos que Mudam a Vida; Comunidade Terapêutica; Saúde da Mulher.

\section{ABSTRACT}

The study aimed to understand the perspective of women in drug recovery on treatment in a therapeutic community. It was conducted in March-April 2016 in a reference therapeutic community northeast of Mato Grosso, with 15 women. We used semi-structured interviews with aid script and data analysis, applied to content analysis. It was observed that women expressed sorrow, anguish and distress as they are separated from their families during treatment, making it difficult to accession and continued the established therapy. Furthermore, they demonstrated dissatisfaction as the form of treatment carried out by not considering the individual characteristics of each woman. However, acknowledge that their current conditions in the therapeutic community are markedly better. New approaches can be incorporated in this type of service, prioritizing the active listening of women and their families in the host and the construction of the treatment plan.

KEYWORDS: Substance-Related Disorders. Life Change Events. Therapeutic Community. Women's Health. 


\section{INTRODUÇÃO}

Historicamente, problemas relacionados ao consumo de álcool e outras drogas eram mais comuns entre os homens, porém, as mudanças no papel social da mulher têm determinado a diminuição dessa diferença, mostrando que a disparidade entre os gêneros tem diminuído".

Nos últimos anos, tem-se observado que no Brasil, apenas durante a internação da mulher em serviços de saúde por intercorrências clínicas, cirúrgicas e obstétricas decorrentes do comportamento aditivo, que os profissionais são informados da situação de dependência, por meio de crises de abstinência ou de atitudes características do uso de drogas ("fissura" e emagrecimento)1.

A partir disso, sugere-se que as mulheres que vivenciam ou estão expostas ao sofrimento em decorrência das drogas devem receber atenção especial desde o primeiro contato ${ }^{2}$. Esse cuidado se configura como oportunidade para o estabelecimento de espaço de inclusão, valorização da diversidade e como recurso auxiliar no resgate da identidade e dignidade, na medida em que ampare sua situação de vulnerabilidade e o do seu sentir-se violentada e "vazia"2,3.

Além disso, há profissionais que foram concebidos em modelos de assistência que não incluem as questões de gênero como fator preponderante para o acolhimento, o que amplia a distância entre o cuidador e 0 ser cuidado, ficando tão longe ainda do alcance das necessidades reais da mulher. Destaca-se que para muitas mulheres, o uso de drogas não é uma questão central em suas vidas, mas sim um meio para suportar a dura realidade que vivenciavam, principalmente por resultar de dores e marcas da violência, perdas, solidão e estigmas ${ }^{4}$.

Acrescenta-se a esta realidade, o fato do não desenvolvimento de estudos sobre as necessidades específicas das mulheres em abuso ou dependência das drogas, o que permite pensar que a particularidade da feminilidade vem sendo marginalizada também no meio científico ${ }^{5}$. Dessa forma, o estudo objetivou conhecer a perspectiva de mulheres em recuperação de drogas sobre o tratamento em uma comunidade terapêutica.

\section{MÉTODO}

Esse estudo compõe a pesquisa intitulada saúde mental: uma abordagem com profissionais de saúde, estudantes, usuários e familiares, cuja aprovação se deu pelo protocolo no 515705, emitido pelo Comitê de Ética em Pesquisa, da Universidade Federal de Mato Grosso (UFMT) que considerou os aspectos éticos de pesquisas com seres humanos preconizados na Resolução 466/2012 do Conselho Nacional de Saúde.

Trata-se de um estudo do tipo descritivo-exploratório, com abordagem qualitativa. Justifica-se a utilização desta abordagem, por ela proporcionar um vasto campo de possibilidades metodológicas para estudos de assuntos ainda pouco conhecidos e explorados ${ }^{6}$.

O estudo foi realizado em uma Comunidade Terapêutica (CT) feminina urbana de um município do interior de Mato Grosso, com capacidade máxima de trinta usuárias. A escolha desse local deu-se por constituir-se na única CT 
feminina compreendida na mesorregião do nordeste matogrossense (fronteira com os estados de Goiás-GO, TocantinsTO e Pará-PA) abrangendo 25 municípios, com uma área geográfica de 177.336,73 km2 e com população de 376.332 habitantes em $2010^{7}$.

Trata-se de uma CT com caráter provisório, religioso e filantrópico, seguindo as orientações vigentes da Portaria MS 3088/2011 e Resolução CONAD N. 01/2015, desenvolvendo cuidados exclusivos a mulheres maiores de 18 anos, em condições clínicas estáveis, com problemas associados ao uso nocivo ou dependência de substância psicoativa. Realiza acolhimento de pessoas, de forma voluntária, por demanda espontânea, judicial ou encaminhadas por outros serviços. Possui ambiente residencial com tratamento médio de nove meses ${ }^{8}$. Sua equipe de profissionais é composta por religiosos sem formação específica e colaboradores voluntários.

A população do estudo foi formada por 15 mulheres em recuperação, as quais atenderam aos seguintes critérios de inclusão: estarem em tratamento há, no mínimo, trinta dias; terem idade entre 18 anos ou mais e aceitarem participar desse estudo, assinando o Termo de Consentimento Livre e Esclarecido (TCLE). Previu-se a exclusão daquelas com agravos que dificultassem sua participação no estudo (o que não ocorreu).

Durante o processo de coleta dos dados que esse quantitativo (15 participantes) foi considerado suficiente, com base na exaustividade das informações de interesse, tal como proposto pela saturação amostral ${ }^{9}$. Considerando a importância de se manter o anonimato das participantes, as mesmas foram identificadas pela codificação do tipo alfanumérica, de modo que a letra M indica mulher, e o elemento numérico sequencial as caracterizou.

A coleta de dados foi realizada através de entrevistas semiestruturadas, as quais duraram em média de 45 minutos e ocorreram durante os meses de março a abril de 2016, na própria comunidade terapêutica. Tais entrevistas foram norteadas por um roteiro e aconteceram individualmente no consultório de enfermagem da CT, por constituir um espaço iluminado, arejado e reservado, o que favoreceu a harmonia e o bem-estar da participante. Para não comprometer as atividades terapêuticas da instituição, as entrevistas foram agendadas previamente junto a direção do serviço.

As respostas das participantes foram gravadas em gravador digital, após o consentimento prévio de cada uma delas e após foram transcritas na íntegra. Para a análise dos dados utilizou-se a Análise de Conteúdo (AC) que interpreta o conteúdo, após leitura detalhada, o que permite o alcance do conhecimento de aspectos e fenômenos da vida social. As linhas de análise foram delimitadas a partir de pré-análise, exploração do material, tratamento dos resultados, inferência e interpretação.

\section{RESULTADO E DISCUSSÃO}

No estudo, identificou-se prevalência de mulheres entre 21 e 30 anos, pardas, protestantes evangélicas, solteiras, com ensino fundamental incompleto, com renda familiar mensal de até um salário mínimo, anterior ao 
tratamento trabalhando informalmente como cuidado do lar e de crianças. Afirmaram terem sofrido violência pelo parceiro, especialmente violência física e psicológica, porém minoria foram coagidas a cometer crimes. Os crimes consumados ocorreram por transporte de drogas e pela entrega de produtos de furto para traficante.

Em relação a filiação das internas, seus pais em geral não apresentavam escolaridade, ambos possuíam alguma dependência química, principalmente pelo álcool, com antecedentes criminais na família. Observou-se que as mulheres estavam em sua primeira internação na CT, mas já tendo buscado tratamento para recuperar das drogas em vários locais, como, no Centro de Atenção Psicossocial Álcool e Drogas (CAPS AD), ministério público, clínicas particulares e hospital psiquiátrico, porém, sem sucesso.

A descoberta deste serviço comunitário ocorreu principalmente por meio de familiares e amigos. Na admissão, prevaleceu aquelas que chegaram sozinhas, quando não, acompanhadas pelos pais ou irmão. Em sua maioria, mostraram-se satisfeitas com a forma que foram recebidas na casa.

\section{Inquietações ao chegar na comunidade terapêutica}

As perdas familiares ocorridas em razão das drogas predominaram como a principal inquietação no momento de chegada ao serviço.

Minha maior dor na verdade, tipo não se relaciona diretamente ao lanche das drogas sabe, mas sim o abandono que tive. O cara me trocou pela droga, ele preferiu a droga. Ele deu toda a vida dele, a casa, a nossa família em troco da droga. Ele me largou na rua gravida [...]. Isso é uma coisa que até hoje tento perdoar, porque agora sou cristã, mas é uma coisa que você não consegue [...], pois a pessoa não merece [...]. (M1)

Quando eu cheguei aqui meu maior sofrimento foi deixar meus filhos para traz [...], [...] eu senti muita falta da minha mãe no começo mesmo quando ela brigava comigo, eu sabia que ela estava brigando pelo bem. Minha mãe e meus filhos senti muita saudade. (M3)

Só meu filhos... só a falta deles [...]. (M4)

Ixi, isso é uma dor que não acaba mais não, vontade de ir embora voltar pra minha casa, não ta com meu marido, nem com meus filhos [...]. (M8)

Ao pensarem que seria difícil exercerem o papel de mãe na ausência dos seus filhos, mesmo com a orientação que o distanciamento ocorreria temporariamente durante sua estadia na $\mathrm{CT}$, isso provocou sensações de tristeza, desamparo e angústia.

Esses sofrimentos não raros, podem se intensificar, uma vez que, apesar de constituírem um espaço comunitário terapêutico, as CT's possuem características de instituições fechadas, criando uma barreira virtual entre o mundo interno 
e externo. E esse distanciamento familiar ao invés de contribuir com adesão ao plano terapêutico instituído pode despertar sofrimentos maiores nem sempre compreendidos pelos cuidadores informais dessas comunidades ${ }^{8}$.

Mas, ainda que o sentimento de abandono, distância e amor pela família comumente gere aflição durante 0 tratamento, expectativas expressas pela esperança de uma nova vida e pela possibilidade de crescimento pessoal na busca de um futuro digno se faz presente.

Quero uma vida descente, saudável e feliz. (M6)

Eu estava agoniada e preocupada, querendo sair de tudo isso que estava vivendo, voltar a ser eu, uma boa mulher, estudando e trabalhando. (M7)

[...] Tenho que dar uma reviravolta na minha vida e me sentir tranquila novamente. Estou descontrolada [...] não posso ter o que quero [...] me falta dinheiro, me falta um tanto de coisas [...]. (M12)

Como revelado pelas mulheres, a retomada de uma vida não mais baseada no consumo de drogas e na dependência de práticas destrutivas, significa a recompensa de um novo tipo de liberdade, agora que se manifesta com calmaria e o retorno de papéis perdidos. A reconstrução da vida expressa pela possibilidade de voltar a fazer planos e executá-los, retornar aos estudos, ao trabalho, controlar as finanças, restituir os vínculos familiares, ou seja, o desejo de mudança e a viabilização de projetos palpáveis tornam-se reais quando as mulheres dizem não e cessam o uso da $\operatorname{droga}^{10}$.

Esse movimento de transição, entre dependência e emancipação frente às drogas fortalece o cuidado terapêutico, na medida que conduz ao autogoverno da mulher e percepção de suas fragilidades. Nesse processo, o cuidador deve enaltecer a integralidade dos progressos e identificar sinais subversivos a esse projeto terapêutico ${ }^{11}$.

\section{Mulher em tratamento de drogas}

Os sofrimentos enfrentados pela mulher diante às drogas, quando acolhida num tratamento, tende a transformálos em fatores para sua mudança, a partir da expectativa de estar prestes a ser coberta de cuidados. Cuidado sensível, cuidado empático, cuidado fraterno, cuidados nem sempre encontrados, como revelado nas narrativas.

Olha depende muito da mulher, [...] tem muita diferença de uma para outra aqui dentro, só que para os cuidadores evangélicos a gente é tudo a mesma coisa, só que eu acho que não deveria ser desse jeito, não é que a outra tem que ser tratada melhor ou pior, mas não é porque a outra faz e sente daquele jeito que você é igual a ela. [...] eu acho que é um tratamento muito mecânico, sem compreensão e você acaba se ferindo ao em vez de ir se curando [...]. (M1)

Uma mulher no tratamento para vencer tem que ser forte, porque parece que a mulher fica mais dependente do que o homem nas drogas. Ela tem mais dificuldade de se tratar, tem muitas que nem ficam aqui por muito tempo, muitas 
fogem. (M3)

[...] aqui é um lugar bom, mas devido ao meu problema, porque sou uma pessoa nervosa, sensível qualquer coisa que falarem, entendeu?! Não acho que aqui seja um lugar ruim só que eu não dou conta de viver trancada, sendo presa [...]. [...] acho que se eu chegasse a ir para uma cadeia, morreria lá dentro, por isso não quis esse mundo para mim. Quando eu sair daqui pedra na minha vida nunca mais [...]. (M8)

Os tratamentos da dependência química, bem como as ações de promoção da saúde e a prevenção do uso de drogas, devem romper com o modelo cartesiano e admitir que reduzir o fenômeno da drogadição em nossa sociedade é algo que depende da interação entre variados grupos, demandando mudanças substanciais na organização social, diminuindo drasticamente as desigualdades presentes nesse contexto ${ }^{3}$.

Também são necessárias mudanças na formação dos profissionais envolvidos no cuidado, além de modificações na forma de encarar o indivíduo que apresenta maior vulnerabilidade em relação à droga, abordando os mesmos como seres ativos nesse processo saúde/doença, que possuem saberes e fazeres próprios. Um dos mecanismos eficazes no enfrentamento à expansão das drogas está a formação de profissionais das diversas áreas, inclusive da saúde, capazes de lidar com as múltiplas facetas que envolvem o fenômeno ${ }^{12}$.

Além disso, o tipo de serviço ofertado, no caso, a CT, promove o isolamento social, o afastamento desse usuário de outros dispositivos sociais fundamentais que permitem e sustentam sua participação na comunidade, o que é questionável enquanto prática terapêutica ${ }^{13}$. A expressividade do discurso que faz o paralelo da CT com uma "prisão", evidencia o sentir-se recluso da mulher.

Entretanto, para que o processo de recuperação química repercuta satisfatoriamente na vida da mulher, alguns discursos indicaram a ressignificação do sofrimento, o que trouxe motivação para conseguirem atravessar as dificuldades impostas nas lembranças e nas ausências.

Eu acho que é bom. (M2)

Uma nova mulher, guerreira. (M4)

Nossa já sofri tanto [...] acho que é com coragem que estou vencendo (M10)

Não tem nem como comparar com antes [...]. (M12)

É de consenso que no processo de recuperação, ou seja, na mudança de vida do usuário de droga, o seu mundo simbólico precisa ser desconstruído e desmantelado numa base social, que seja um "laboratório para sua transformação". Assim, algumas lembranças serão gradativamente dissipadas outras, no entanto, resistirão fortemente, o que pode 
auxiliar na reflexão do novo ${ }^{14}$. Ainda que, já em tratamento, essas mulheres apresentam sentimento de impotência em ter buscado uma esfera terapêutica e se permitem diminuir ou consentir essa sensação.

[...] É um desespero ver que está longe da família por sua causa mesmo [...]. (M5)

[...] Uma mulher drogada que se perdeu e não conseguiu se levantar sozinha. (M6)

Pequena... pequena. (M11)

Como observado, o estigma, a vergonha e a culpa são sentimentos comuns vivenciados por essas mulheres antes, durante e após o tratamento. Como resultado, esses sentimentos e a sensação de "fracasso" aniquila a percepção de chegada à altura de papéis e expectativas sociais, tornando ainda maior o desafio do cuidado terapêutico implementado durante o tratamento, já que normalmente essas mulheres não possuem espaços para dialogar sobre seus sofrimentos, não verbalizando e cronificando suas experiências danosas 4 .

Assim, a criação de espaços para manifestação de expressões de alegria e dor das mulheres, como também o apoio emocional oferecido pelos cuidadores deve ser empregado principalmente naqueles momentos efêmeros de motivação, na tentativa de utilizar essa condição como um reforço positivo duradouro individual, com extensão ao coletivo de mulheres em tratamento ${ }^{15}$.

Nessa razão, a dinâmica terapêutica das CTs deve propiciar criação de grupos que permitam as participantes o partilhar de suas histórias, sentimentos e receios, facilitando a compreensão do seu sofrimento e desafios no relato de outras usuárias. Esse trabalho é considerado um fator protetivo, pois além de oferecerem apoio emocional, também tem caráter educativo, auxiliando a usuária no enfrentamento e manejo dos fatores de riscos ${ }^{16}$.

\section{Percepções após início do tratamento}

A imagem da mulher com indicativos de resiliência no tratamento da dependência química, pode ser a melhor experiência para os cuidadores e familiares, por fortalecer o comprometimento e a esperança, mas mostra-se mais significativo quando o sentir-se saudável e fortalecida provém da auto percepção da mulher.

Bem melhor do que antes. (M2)

Agora eu estou bem graças Deus. [...] Não sinto falta de nada, de nada mesmo graças a deus. Quero ficar longe do meu passado. (M3)

To sentindo melhor, sentindo mais apoio, mais apoiada e ajudada por todos aqui na casa. (M4)

Agora estou bem, só estou com vontade de ir embora [...] juntar minhas coisas, partir e ter uma nova vida. (M8) 
Conforme os discursos, as mulheres demonstram revigoradas a partir do tratamento e mais confiantes na recuperação. Movimento esse, que repercute na vida da mulher, especialmente no estabelecimento de objetivos, direcionados à construção de um novo projeto de vida ${ }^{17}$.

Entretanto, ainda que haja outras recaídas até o término do tratamento, possuir retorno positivo diante da terapia, harmoniza a interação entre os envolvidos e o ambiente de cuidado, o que intensifica o estado de bem-estar, satisfação frente a melhora do seu estado de saúde, além de promover autocontrole e o distanciamento de experiências com a droga $^{18}$. Todavia, há mulheres que não reconhecem algumas normas da CT como estratégias de cuidado e isso resulta em dificuldade de se manterem no tratamento.

[...] desde o início do tratamento, eu me questiono até hoje, porque você acredita num tratamento, mas os próprios profissionais que estão te tratando não acredita em você. Eu estou com nove meses aqui, mesmo eu sendo dependente química e eu vim para cá somente para conseguir pegar meu filho de volta, e nem a visita dele eu posso ter. Então que esperança que eu posso ter de um tratamento desse, se eu não posso nem ver meu filho. (M1)

O ruim é só que não podemos sair [...] é difícil de segurar aqui [...] longe do meu ambiente familiar. (M6)

Percebe-se que as mulheres se veem sendo cuidadas na perspectiva de um tratamento uniforme que não inclui suas famílias e seus entes queridos. O que para alguns pesquisadores pode atrapalhar a incorporação de redes de apoio que auxiliam na descoberta de recursos emancipatórios, uma vez que o contato e coparticipação da família durante 0 processo terapêutico da mulher, quando bem direcionado pelos profissionais produzem melhores desfechos, reduzindo novas internações ${ }^{10,19}$.

Outras mulheres dessa comunidade reconhecem que melhoraram significativamente ao repensarem como eram/ estavam anterior ao tratamento. Porém, a luta contra a abstinência parece ser um desafio diário e demandar inúmeros recursos individuais para o enfrentamento.

São dias longos de resistência para não sair e comprar droga. Vou até o fim [...]. (M5)

Bem, mas com muita vontade de fumar. Venho sendo forte [...]. Conheci boas pessoas aqui dentro, são mais velhas na casa, aí caminham comigo [...] (M7)

Não sei se estou bem por que ainda sinto falto do meu cigarrinho, mas melhor que antes. Aprendo todos os dias ficar longe disso. O pastor ajuda muito nisso [...] (M11)

A abstinência pode ser interpretada como um esforço assistido de reconhecimento do problema, de retorno à família, de recuperação da autoestima, de se evitar o contexto propiciador à adição, do envolvimento em trabalhos de recuperação de outros dependentes e, por fim, de um sentido prospectivo de existência ${ }^{20}$. 
A manutenção da abstinência exige o reconhecimento das pessoas de sua condição e o distanciamento delas e de situações favoráveis à recaída. Para tanto, alguns recursos externos tais como a espiritualidade/religiosidade e o afeto da família favorecem essa manutenção ${ }^{21}$.

Outrossim, deve-se considerar a habilidade em recusar a droga para que se possibilite a manutenção da abstinência e esse comportamento social dependerá das construções estabelecidas internamente durante o tratamento e do contexto de vida posterior ao mesmo 22 .

Apesar disso, sustentar esse novo estilo de vida, com abandono total da substância que em outrora representava um grande desejo, mostra-se uma tarefa árdua, ao limitar à individualidade, porém com a participação de outros membros dessa ambiência ocorre maior fortalecimento, auxiliando no trajeto até a alta da comunidade terapêutica ${ }^{23}$.

\section{CONSIDERAÇÕES FINAIS}

No estudo, ficou evidente que para essas mulheres, o distanciamento da família representou o maior sofrimento ao ingressar na CT. Situação que parece ter forte influência na adesão e continuidade ao tratamento estabelecido, bem como no reconhecimento desse espaço terapêutico como (in)apropriado à recuperação das drogas.

Ao iniciar o tratamento, as mulheres vislumbram a ausência de cuidadores com recursos terapêuticos suficientes à distinção das características de cada mulher, tratando a coletividade sem compreender suas especificidades, levando a situações de isolamento social e fugas. Algumas, porém, assentem essa dinâmica terapêutica por temer formas de repressão e violência fora da CT. No entanto, com o avançar do tratamento se veem vitoriosas ao refletir sobre suas vivências danosas anteriores e sua condição atual, mas persiste ainda a carência de formas de afeto particular.

Essa constatação faz acreditar que novas formas de abordagem podem ser incorporadas nesse tipo de serviço, priorizando a escuta ativa da mulher e de seus familiares no acolhimento e na construção do projeto terapêutico. De forma que, a relação entre cuidador e ser cuidado seja estabelecida cotidianamente, baseada na ética, no respeito e na autonomia da mulher.

\section{REFERÊNCIAS}

1. Marangoni SR, Oliveira MLF. Fatores desencadeantes do uso de drogas de abuso em mulheres. Texto \& contexto enferm. 2013; 22(3):662-670.

2. Diehl A, Figlie NB. Prevenção ao uso de álcool e drogas: O Que Cada um de Nós Pode e Deve Fazer? Porto Alegre: Artmed; 2014. 
3. Pratta EMM, Santos MA. O Processo Saúde-Doença e a Dependência Química: Interfaces e Evolução. Psicol teor pesqui. 2009; 25(2):203-211.

4. Bolzan LM. Onde estão as mulheres? A homogeneização da atenção à saúde da mulher que faz uso de drogas. Porto Alegre: [s.n.], 2015. 150 p. Dissertação (Mestrado) - Pontifícia Universidade Católica do Rio Grande do Sul, 2015.

5. Venosa PAS. Grupos psicoterapêuticos de mulheres dependentes químicas: questões de gênero implicadas no tratamento. Rev SPAGESP. 2011; 12(1):56-65.

6. Gil AC. Como elaborar projetos de pesquisa. São Paulo: Atlas; 2010.

7. Brasil. Instituto Brasileiro de Geografia e Estatística - IBGE. Censo demográfico do Brasil. Brasília: IBGE; 2010.

8. Ronzani TM, Costa PHA, Mota DCB, Laport TJ. Redes de atenção aos usuários de drogas: políticas e práticas. São Paulo: Cortez; 2015.

9. Fontanella BJB, Luchesi BM, Saidel MGB, Ricas J, Turato ER, Melo DG. Amostragem em pesquisas qualitativas: proposta de procedimentos para constatar saturação teórica. Cad saúde pública. 2011; 27(2):389-94.

10. Gomes RR, Ribeiro MC, Mattias EC, Brêda MZ, Mângia EF. Motivações e expectativas na busca de tratamento para o uso. Rev ter ocup. 2015; 26(3):326-335.

11. Lima MDA, Souza AS, Dantas MF. Assistência social e ações de enfrentamento ao crack e outras drogas: um debate necessário. Rev interfaces. 2016; 3(11):95-102.

12. Wright MGM, Gliksman L, Khenti A, Furegato ARF. A pesquisa sobre o fenômeno das drogas na perspectiva dos estudos multicêntricos na américa latina e caribe. Rev latinoam enferm. 2009; 17:751-3.

13. Damas FB. Comunidades Terapêuticas no Brasil: expansão, institucionalização e relevância social. Rev saúde pública. 2013; 6(1):50-65. 
14. Crauss RMG, Abaid JLW. A dependência química e o tratamento de desintoxicação hospitalar na fala dos usuários. Contextos Clín. 2012; 5(1): 62-72.

15. Lopes RE, Nóbrega-Therian SM, Araújo PA, Gomes BV, Cavalcanti MMB. Quando o conviver desvela: assistência de saúde mental às mulheres com familiares usuários de droga. Sanare. 2015; 14(1):22-26.

16. Silva $\mathrm{ML}$, Guimarães $\mathrm{CF}$, Salles $\mathrm{DB}$. Fatores de risco e proteção à recaída na percepção de usuários de substâncias psicoativas. Rev Rene. 2014; 15(6):1007-15.

17. Silva RL, Borrego ALS, Figlie NB. Psicoterapia de grupo. In: Diehl AE, Cordeiro DC, Laranjeira, R. Dependência química: prevenção, tratamento e políticas públicas. Porto Alegre: Artmed; 2011.

18. Bittencourt ALP, França LG, Goldim JR. Adolescência vulnerável: fatores biopsicossociais relacionados ao uso de drogas. Rev Bioét. 2015; 23(2):311-319.

19. Carvalho FRM, Brumarello T, Guimarães NA, Paes MR, Maftum MA. Causas de recaída e de busca por tratamento referidas por dependentes químicos em uma unidade de reabilitação. Colomb med. 2011; 42(2):57-62.

20. Favaro F, Paula SR. Dependentes químicos: o perfil da abstinência de drogas. J Health Sci Inst. 2012; 30(1):41-3.

21. Sanches JFA, Almeida KPB, Magalhães JM. O significado dos usuários de álcool e outras drogas sobre recaídas. Rev Interdisciplin. 2015; 8(2):53-59.

22. Souza MCH, Mühlen BKV, Coelho LRM, Oliveira CP, Rodrigues VS, Oliveira MS et al. Assertividade em muIheres dependentes de crack. Aletheia. 2014; 43-44: 105-115.

23. Coelho LRM, Sá LGC, Oliveira MS. Estratégias e Habilidades de Enfrentamento de Usuários de Crack em Tratamento. Rev psicol IMED. 2015; 7(2):99-109. 